of the tenement, no fewer than twenty of whom died before the history was closed. R. H. was admitted to hospital on September r4th, with a history of three days fever. He had ose day's fever in the hospital with ho delirium and no fever. He had one day's fever in the hospital with cuppurated but healed quickly, and he was ready for discharge on October 2 nd,

CASE v.-Óne other case, S. M., from the David Sassoon Hospital, was said to have been inoculated there on October 3 rd, 1900 plague having appesred among the hospital servants. She was admitted on Uctober 5 th with a history of two days fever. She was very ill, with a temperature of $203^{\circ}$ to $105^{\circ}$, restless and delirious, with constant vomiting, and died on October 6 th, within twenty-four hours of admission.

Thus it will be seen of 5 cases who were living in highly infected centres at the time of inoculation, and who probably had plagne on them, in at least 2 cases where inoculated there was one death only, that is, a recovery-rate of 80 per cent.

\section{THE TREATMENT OF DYSENTERY BY RECTAL INJECTIONS.}

By CECIL F. LILLIE, M.A., M.D.Cantab. Late Civil Surgeon to H.M. Field Force, S. Africa.

THIS form of treatment does not appear to be very warmly supported. I have tried it myself in several cases in South Africa and found it most useful.

The method I employed was as follows: I used an apparatus composed of a soft oesophageal catheter. attached by a piece of glass tubing to some soft rubber tubing about 3 feet in length; to this was fixed a large glass funnel. The patient was placed on his leit side and the hips drawn over to the edge of the bed. The knres being flexed, the end of the catheter, smfared with vaseline, was introduced into the rectum with the greatest care, the patient being directed to strain meanwhile. Cocaine was used for the anus if required. The catheter was introduced about 4 inches without using any force. The patient then being placed gently on his face, the hips well raised on pillows, and the head and shoulders placed low, the warm lotion was introduced without any difficulty into the bowel. The apparatus was previously filled with lotion, and a clamp applied so as to avoid injecting air into the bowel. By raising or lowering the funnel the rate of injecting the solution was readily regulated. Small quantities only were allowed to run in slowly at a time-an ounce or so every few seconds. The enema was retained if possible for a few minutes. I gave these injections usually two or three times a day. It is an important point to give them often enough. I generally used boracic acid-10 grs. to the ounce-sometimes other antiseptics.

Using injections in this way, I never found them displeasing to the patients; several in fact expressed a wish to have them repeated. The pain often felt at first was soon overcome by allowing only a small quantity of the solution to pass into the bowel slowly at one time. The bulk of the enema was never less than a pint and a-half. Smaller ones are useless.

The value of injections in chronic cases is well known. In mild acute cases I found them uniformly successful. The tools were diminished in frequency and became faeculent and semisolid within three days. Relapses were uncommon. In the malignant cases, occurring generally in epidemics, the ase of injections is somewhat doubtful, but it is difficult to get hold of these cases early enough to hope for good results. Unfortunately the process is so rapid that when they come ander treatment there is already much destruction of tissue, and a satisfactory cure is impossible. In severe cases, however, injections are not useless; one case showed this very well. The patient was very ill on admission. He was passing borribly offensive stools which contained sloughs and a good deal of blood. He died some nine days after admission from hepatic abscess. Rectal injections of boracic acid had been given regularly, and the stools were reduced in number to two a day; the blood disappeared from them, and they ceased to be offensive. At the necropsy twenty to forty dysenteric nlcers were found; they were all looking healthy, and presented signs of healing. There were no sloughs, their bases were smooth and the edges were spreading over the raw surfaces. The liver was full of large abscesses. In this case the condition of the ulcers bore striking testimony to the usefulness of the injections.
The objections raised to this form of treatment are that it is dangerous and often impracticable. The danger of causing perforation by giving injections only applies in those case where the bowel is extensively and deeply ulcerated. However, in such a condition it is too late to expect much good to come from any treatment. Such cases are obviously hopeless, and their clinical appearance is a sufficient safeguard from a rash use of injections. It is before this last stage of the disease is reached that good may be expected from them.

With regard to perforation in dysentery, I found that out of 2,7 II cases whose records I examined perforation had only occurred five times. In these, too, the perforations were small and surrounded by dense adhesions which completely shut them off from the peritoneal cavity. In all the cases I examined post mortem myself I noticed marked thickening of the bowel generally, and more especially at the seat of ulceration. Injections are said to be impracticable owing to the pain caused by forcing apart the walls of the inflamed gut. By administering the injections with due care I think this can be largely avoided.

The saline treatment of dysentery acts, I believe, on the same principle as this. In both cases the bowel is flushed out and the toxic substances removed, and with them the griping and tenesmus which they induce. Injections possess the advantage of introducing the fluid for this flushing from without instead of draining it from the patient's already weakened system. Another advantage is that antiseptics can be directly applied to the focus of the disease.

In addition to injections the patient must of course be kep absolutely at rest in bed and fluid nourishment given in small quantities at frequent intervals. Milk diluted is best. Chicken broth is often useful. Stimulants are generally required.

\section{MEMURANDA:}

MEDICAL, SURGICAL, OBSTETRICAL, THERAPEUTICAL, PATHOLOGICAL, ETC.

\section{OBSERVATIONS DURING A RESIDENCE OF EIGHTEEN MONTHS IN EAST AFRICA AND UGANDA.}

Since my arrival in Africa on April 27th, 1900, the following methods of treating such tropical diseases as I have come across, having been found very successful by me, may be of use to others.

In malarial fever, with dry brown tongue and constant vomiting, with a temperature of $104^{\circ}$ or more, I have not withheld quinine until the pyrexia has abated, as is taught, but, instead of giving it by the mouth to be vomited up again, I find that three or four 5-grain tabloids, with two of phenacetin, greased with vaseline, and inserted into the rectum, brings the fever quickly under control. I have noticed in those places where I have been stationed, the Anopheles type of mosquito has been conspicuous by its absence, and to bear out the theory that this noxious insect is the vehicle for conveying the malarial parasite to man, I have been unable to discover one case of malarial infection directly traceable to these districts.

Dysentery. - I have so far found that powdered ipecacuanha $3 j$, with laudanum $m \times x$ to $x \times v$, mixed with water $\xi i j$, and injected into the rectum, works. wonders, one to three such injections 1 have found sufficient, my patients' diet being rice water and albumen water. Native cooking pots are made of copper, tinned over very indifferently. This tin quickly wears off, and dysenteric symptoms may be produced by copper oxide poisoning. Iron pots are the safest and I have banished all native utensils made of copper from my kitchen.

Ulcers from Chiggers.- I saw a vast number of these and on my arrival at Samu was told that iodoform ointment was the treatment. It does not, however, remove the cause. Caustic such as carbolic acid to kill the ova are required. Toes infiltrated with the eggs invariable ulcerated down to the base and then dropped off. The best treatment I found was that which I have used for carbuncle, guinea worm ulcers, etc.. namely hypodermic injections of mercury biniode or perchloride all round the infected zone.

Chiggers in Houses.-Of these pests I have had bitter per- 